\title{
Impact of Conventional and Electronic Cigarette Use on the Adolescents' Experience of Periodontal Disease Symptoms
}

\author{
Eunsuk $\mathrm{Ahn}^{1}$ and Jin-ha Lee, ${ }^{2, \dagger}$ \\ 'Division of Climate Change and Health Protection, Korea Disease Control and Prevention Agency, Cheongju \\ 28161, ${ }^{2}$ Department of Dental Hygiene, Kyungbok University, Namyangju 12051, Korea
}

\begin{abstract}
Background: Smoking in adolescence leads to an intensified addiction to nicotine when physical and mental growth has not yet been completed. With the advent of e-cigarettes, the rate of e-cigarette use among Korean adolescents has been steadily increasing. To date, studies on e-cigarettes and oral health, especially on the relationship between smoking styles and oral health in adolescents, are limited. Therefore, this study aimed to identify the risk factors for oral health problems caused by the repeated use of conventional cigarettes and e-cigarettes.

Methods: This explanatory research study compared the adolescents' experiences of periodontal disease symptoms according to smoking type through a secondary analysis of the original data from the 15th Adolescent Health Behavior Survey (2019). Cross-analysis was performed to compare the smoking patterns according to the adolescents' general characteristics. Finally, a binary logistic regression analysis was performed to determine how smoking characteristics affect the adolescents' experience of periodontal disease symptoms.

Results: In terms of patients' general characteristics, significant differences were observed in sex, school level, grades, household economic status, type of residence, and father's education level between adolescents who smoked conventional cigarettes alone and those who smoked both conventional cigarettes and e-cigarettes $(p<0.05)$. After checking the factors affecting the smoking pattern and the experience of periodontal disease symptoms in adolescents, it was found that the duplicate smoking group was more likely to experience periodontal disease symptoms (odds ratio, 1.20) than the group that smoked conventional cigarettes alone $(\mathrm{p}<0.05)$.

Conclusion: Duplicate smokers experienced more symptoms of periodontal disease than those who smoked cigarettes alone. Based on the findings of this study, smoking cessation counseling according to the smoking type and differentiated education for oral health promotion should be provided.
\end{abstract}

Key Words: Adolescent, E-cigarette, Periodontal disease, Smoking cessation

\section{Introduction}

Smoking is the direct cause of various diseases such as lung cancer and oral cancer, and has long-term adverse effects such as mental health problems, environmental pollution, and economic damage ${ }^{1)}$. Smoking in adolescence leads to an increase in addiction to nicotine when physical and mental growth has not yet been completed; hence, the damage caused by smoking is inevitably increased ${ }^{2,3)}$.

With the advent of liquid e-cigarettes in 2003, the rate of e-cigarette use among Korean adolescents is steadily increasing. This is perceived as a result of the misconception that e-cigarettes are smoking cessation tools and products that are less harmful to health than conventional cigarettes ${ }^{4}$. In particular, e-cigarette smoking in adolescents can have a negative effect on brain development, and adolescents who do not smoke conventional cigarettes are persuaded to increase e-cigarette smoking ${ }^{5)}$. According to previous studies, $80.8 \%$ of e-cigarette smokers use it along with conventional cigarettes, and the duplicate smoking rate is 
increasing ${ }^{6)}$.

Smoking is an act performed in the oral cavity, and it directly affects the soft and hard tissues, causing various oral diseases such as tooth staining, bad breath, periodontal disease, and oral cancer. It has a detrimental effect on oral health $^{7,8)}$. The longer the smoking period, the higher the rate of dental utilization; moreover, the higher the cost of dental treatment, the higher the expenses incurred ${ }^{9)}$. Compared with conventional cigarettes, due to the high viscosity and flavor of the liquid used in e-cigarettes, the environment in the oral cavity changes, causing an imbalance in the oral flora and the adherence of these bacteria to the tooth surface, eventually causing dental caries $^{10,11)}$. This event was found to increase the plaque index, which is one of the major causes of dental caries and periodontal disease ${ }^{12)}$.

Smoking cessation not only reduces the risk of oral disease but also increases the effectiveness of dental treatments. Therefore, dental healthcare workers should be actively involved in promoting smoking cessation. The rate of e-cigarette use among adolescents is dramatically increasing due to the misconception regarding the safety of e-cigarettes; the rate of duplicate smoking among conventional cigarette smokers and e-cigarette smokers continues to increase as well. It has been reported to be much higher than the rate of conventional smoking ${ }^{5,8)}$. However, there is a lack of studies on e-cigarettes and oral health, especially regarding the relationship between the type of smoking and oral health among adolescents. Therefore, this study aimed to identify the risk factors affecting smoking type and the adolescents' experience of periodontal disease symptoms, a frequent oral disease in adolescents, by assessing the demographic characteristics and obtaining basic data on the interventions used to reduce smoking among adolescents and the different strategies adopted to promote oral health.

\section{Materials and Methods}

\section{Study population}

This explanatory survey compared the oral health of adolescents according to smoking type by performing a secondary analysis of the data from the 15th Adolescent
Health Behavior Survey (2019). The Youth Health Behavior Survey is a government-approved statistical survey (approval number: 117058) and has been conducted every year since 2005. It is an anonymous, self-written online survey to determine the health behaviors of Korean adolescents, such as smoking. It was carried out after receiving approval from the Korea Disease Control and Prevention Agency for the use of raw data. A total of 60,100 adolescents from 400 middle schools and 400 high schools were invited to participate in the survey. Among them, only 57,303 adolescents from the 800 schools responded to the survey, which accounts for $95.3 \%$ of the total study population. The study included 3,817 adolescents who smoked cigarettes. Among them, 1,903 adolescents smoked conventional cigarettes alone, while 1,914 who repeatedly used e-cigarettes.

\section{Study variables}

As the dependent variable of this study, the question of "Have your gums hurt or bleed in the last 12 months?" was used to determine the patients' experience of periodontal disease symptoms. Smoking type was used as an explanatory variable. Adolescents who answered "more than 1 day" to the question "In the last 30 days, how many days did you smoke even one cigarette?" were classified as current smokers. Among the current smokers, those who answered "none" to the question "How many days did you use the e-cigarette in the last 30 days?" were classified as "conventional smokers." In addition, adolescents who answered "more than 1 day" were classified as "duplicate smokers" who used both conventional cigarettes and e-cigarettes. In addition, the other variables assessed in this study were sex (male/female), family economic status (high/middle/ low), school achievement (high/middle/low), living area (county/small and medium-sized city/large city), residence type (living with families/living with relatives/living apart from one's own families [housing, self-catering, dormitory]/ living in a childcare facility), school grade (middle school/high school [general]/high school [characterization]), and parents' education level (below high school/above college/unknown). 


\section{Statistical analysis}

In this study, a frequency analysis was performed to assess the general characteristics of the study participants, and a cross-analysis was performed to confirm the differences in smoking types according to the participants' general characteristics. Finally, a binary logistic regression analysis was performed to determine the effect of smoking type on periodontal disease symptom experience. STATA software (version 14.0; StataCorp, College Station, TX, USA) was used to perform all statistical analyses, and the statistical significance level was set at 0.05 .

\section{Results}

\section{General characteristics of the study population}

Table 1 shows the general characteristics of the study population who smoked. Approximately $71.55 \%$ of the participants were males, which is higher than the proportion of females (28.45\%). The "middle" group had the highest percentage of adolescents with data on school achievement (66.33\%). In terms of smoking type, $49.86 \%$ of adolescent smokers only used conventional cigarettes, while 50.14\% of duplicate smokers used both conventional cigarettes and e-cigarettes.

\section{Differences in smoking types according to the participants' general characteristics}

Table 2 shows the results of the analysis of the differences between conventional cigarette smokers and duplicate smokes according to the general characteristics of the study population. Significant differences were observed in the smoking types according to sex, school grade, school achievement, family economic status, residence type, and father's educational level $(p<0.05)$. In particular, the rate of duplicate smoking was high among adolescents with higher school achievements, and 62.32\% of smokers in the "high" household economic status group smoked repeatedly. In addition, $77.19 \%$ of adolescents living in childcare facilities were found to be duplicate smokers.

\section{Factors affecting the experience of periodontal disease symptoms}

Table 3 shows the results of the logistic regression analysis to determine the factors influencing the smoking patterns and periodontal disease symptom experience in adolescents. The factors that had a significant influence on the experience of periodontal disease symptoms were sex, school grade, residence type, and smoking type $(\mathrm{p}<0.05)$. Among them, females were more likely to experience periodontal disease symptoms than males (odds ratio, 1.73). Depending on the school grade, compared with middle school students, specialized high school students experienced fewer symptoms of periodontal disease. In terms of residence type, the group living in a childcare

Table 1. General Characteristics of Study Population

\begin{tabular}{|c|c|c|c|}
\hline & Variable & $\mathrm{n}$ & $\%$ \\
\hline \multirow[t]{2}{*}{ Sex } & Male & 2,731 & 71.55 \\
\hline & Female & 1,086 & 28.45 \\
\hline \multirow[t]{3}{*}{ School grade } & Middle school & 959 & 25.46 \\
\hline & High school (general) & 1,797 & 47.72 \\
\hline & $\begin{array}{l}\text { High school } \\
\text { (characterization) }\end{array}$ & 1,010 & 26.82 \\
\hline \multirow{3}{*}{$\begin{array}{l}\text { School } \\
\text { achievement }\end{array}$} & High & 368 & 9.64 \\
\hline & Middle & 2,532 & 66.33 \\
\hline & Low & 917 & 24.02 \\
\hline \multirow[t]{3}{*}{ Living area } & Country & 336 & 8.80 \\
\hline & Middle and small city & 1,847 & 48.39 \\
\hline & Large city & 1,634 & 42.81 \\
\hline \multirow{3}{*}{$\begin{array}{l}\text { Family economic } \\
\text { status }\end{array}$} & High & 475 & 12.44 \\
\hline & Middle & 3,134 & 82.11 \\
\hline & Low & 208 & 5.45 \\
\hline \multirow[t]{4}{*}{ Residence type } & Living with families & 3,511 & 91.98 \\
\hline & Living with relatives & 50 & 1.31 \\
\hline & $\begin{array}{l}\text { Living apart from one's } \\
\text { own families }\end{array}$ & 199 & 5.21 \\
\hline & $\begin{array}{l}\text { Living in a childcare } \\
\text { facility }\end{array}$ & 57 & 1.49 \\
\hline \multirow[t]{3}{*}{ Father's education } & Below high school & 790 & 20.70 \\
\hline & Above college & 987 & 25.86 \\
\hline & Unknown & 2,040 & 53.45 \\
\hline \multirow{3}{*}{$\begin{array}{l}\text { Mather's } \\
\text { education }\end{array}$} & Below high school & 830 & 21.74 \\
\hline & Above college & 945 & 24.76 \\
\hline & Unknown & 2,042 & 53.50 \\
\hline \multirow[t]{2}{*}{ Type of cigarette } & $\begin{array}{l}\text { Conventional cigarette } \\
\text { user }\end{array}$ & 1,903 & 49.86 \\
\hline & Duplicate cigarette user & 1,914 & 50.14 \\
\hline \multirow{2}{*}{$\begin{array}{l}\text { Oral symptoms } \\
\text { experience }\end{array}$} & No & 2,985 & 78.20 \\
\hline & Yes & 832 & 21.80 \\
\hline
\end{tabular}


Table 2. Comparison of Type of Cigarette Usage according to General Characteristics

\begin{tabular}{|c|c|c|c|c|c|c|c|}
\hline & \multirow[t]{2}{*}{ Variable } & \multicolumn{2}{|c|}{$\begin{array}{l}\text { Conventional } \\
\text { cigarette user } \\
\quad(n=1,903)\end{array}$} & \multicolumn{2}{|c|}{$\begin{array}{l}\text { Duplicate } \\
\text { cigarette user } \\
(\mathrm{n}=1,914)\end{array}$} & \multirow[t]{2}{*}{$\chi^{2}$} & \multirow[t]{2}{*}{ p-value } \\
\hline & & $\mathrm{n}$ & $\%$ & $\mathrm{n}$ & $\%$ & & \\
\hline \multirow[t]{2}{*}{ Sex } & Male & 1,255 & 45.95 & 1,476 & 54.05 & 58.46 & $<0.001$ \\
\hline & Female & 648 & 59.67 & 438 & 40.33 & & \\
\hline \multirow[t]{3}{*}{ School grade } & Middle school & 524 & 54.64 & 435 & 45.36 & 11.69 & $<0.001$ \\
\hline & High school (general) & 862 & 47.97 & 935 & 52.03 & & \\
\hline & High school (characterization) & 494 & 48.91 & 516 & 51.09 & & \\
\hline \multirow[t]{3}{*}{ School achievement } & High & 144 & 39.13 & 224 & 60.87 & 23.29 & $<0.001$ \\
\hline & Middle & 1,319 & 52.09 & 1,213 & 47.91 & & \\
\hline & Low & 440 & 47.98 & 477 & 52.02 & & \\
\hline \multirow[t]{3}{*}{ Living area } & Country & 166 & 49.40 & 170 & 50.60 & 2.55 & 0.28 \\
\hline & Middle and small city & 945 & 51.16 & 902 & 48.84 & & \\
\hline & Big city & 792 & 48.47 & 842 & 51.53 & & \\
\hline \multirow[t]{3}{*}{ Family economic status } & High & 179 & 37.68 & 296 & 62.32 & 43.28 & $<0.001$ \\
\hline & Middle & 1,640 & 52.33 & 1,494 & 47.67 & & \\
\hline & Low & 84 & 40.38 & 124 & 59.62 & & \\
\hline \multirow[t]{4}{*}{ Residence type } & Living with families & 1,777 & 50.61 & 1,734 & 49.39 & 22.72 & $<0.001$ \\
\hline & Living with relatives & 17 & 34.00 & 33 & 66.00 & & \\
\hline & Living apart from one's own families & 96 & 48.24 & 103 & 51.76 & & \\
\hline & Living in a childcare facility & 13 & 22.81 & 44 & 77.19 & & \\
\hline \multirow[t]{3}{*}{ Father's education } & Below high school & 413 & 52.28 & 377 & 47.72 & 5.85 & $<0.05$ \\
\hline & Above college & 510 & 51.67 & 477 & 48.33 & & \\
\hline & Unknown & 980 & 48.04 & 1,060 & 51.96 & & \\
\hline \multirow[t]{3}{*}{ Mather's education } & Below high school & 432 & 52.05 & 398 & 47.95 & 4.67 & 0.10 \\
\hline & Above college & 486 & 51.43 & 459 & 48.57 & & \\
\hline & Unknown & 985 & 48.24 & 1,057 & 51.76 & & \\
\hline
\end{tabular}

p-value of chi-squared test.

facility experienced more symptoms of oral disease than the group living with the family (odds ratio, 2.07). Depending on the type of smoking, the duplicate smoking group experienced more symptoms of periodontal disease than the group that only smoked conventional cigarettes (odds ratio, 1.20).

\section{Discussion}

In this study, the factors influencing the experience of periodontal disease symptoms in adolescents were analyzed by dividing them into conventional cigarette smokers and duplicate smokers who used e-cigarettes. In $50.14 \%$ of adolescent smokers in the study, duplicate smokers who used both conventional and electronic cigarettes were identified. This value is somewhat lower than the adult's duplicate smoking rate ${ }^{6}$; however, in adolescents, due to the misconception that e-cigarettes are safer than conventional cigarettes, more attention should be paid to decreasing the rate of e-cigarette use among this group ${ }^{13)}$; an increase in the use of e-cigarettes can lead to an increase in the rate of duplicate smoking ${ }^{14,15)}$. The active publicity and education on factors that have a negative impact on health and the risk of duplicate smoking among adolescents are necessary.

As a result of examining the factors influencing the periodontal symptom experience, significant differences were observed according to sex, which is due to differences in socioeconomic status such as smoking rate, education level, and economic level. This is thought to be due to the changes in the physiological balance between anabolic and catabolic mechanisms associated with smoking. In addition, it appears to support the results of existing studies showing some differences in plaque control and periodontal 
Table 3. Factors Affecting Experience of Periodontal Disease Symptoms

\begin{tabular}{|c|c|c|c|c|c|}
\hline & Variable & Odds ratio & $\begin{array}{l}\text { Standard } \\
\text { error }\end{array}$ & $\mathrm{z}$ & $\begin{array}{c}95 \% \\
\text { confidence interval }\end{array}$ \\
\hline \multirow[t]{2}{*}{ Sex } & Male & & & & \\
\hline & Female & 1.73 & 0.15 & 6.39 & $1.46 \sim 2.05$ \\
\hline \multirow[t]{3}{*}{ School grade } & Middle school & & & & \\
\hline & High school (general) & 0.87 & 0.08 & -1.44 & $0.72 \sim 1.05$ \\
\hline & High school (characterization) & 0.71 & 0.08 & -3.03 & $0.57 \sim 0.89$ \\
\hline \multirow[t]{3}{*}{ School achievement } & High & & & & \\
\hline & Middle & 0.95 & 0.14 & -0.36 & $0.72 \sim 1.26$ \\
\hline & Low & 1.01 & 0.16 & 0.06 & $0.74 \sim 1.37$ \\
\hline \multirow[t]{3}{*}{ Living area } & Country & & & & \\
\hline & Middle and small city & 1.09 & 0.17 & 0.59 & $0.81 \sim 1.47$ \\
\hline & Big city & 1.11 & 0.17 & 0.68 & $0.82 \sim 1.50$ \\
\hline \multirow[t]{3}{*}{ Family economic status } & High & & & & \\
\hline & Middle & 1.00 & 0.13 & -0.01 & $0.78 \sim 1.28$ \\
\hline & Low & 1.09 & 0.23 & 0.41 & $0.72 \sim 1.65$ \\
\hline \multirow[t]{4}{*}{ Residence type } & Living with families & & & & \\
\hline & Living with relatives & 0.79 & 0.30 & -0.62 & $0.38 \sim 1.66$ \\
\hline & Living apart from one's own families & 1.09 & 0.20 & 0.47 & $0.76 \sim 1.56$ \\
\hline & Living in a childcare facility & 2.07 & 0.62 & 2.45 & $1.16 \sim 3.72$ \\
\hline \multirow[t]{3}{*}{ Father's education } & Below high school & & & & \\
\hline & Above college & 0.96 & 0.13 & -0.29 & $0.74 \sim 1.25$ \\
\hline & Unknown & 1.06 & 0.16 & 0.40 & $0.79 \sim 1.42$ \\
\hline \multirow[t]{3}{*}{ Mather's education } & Below high school & & & & \\
\hline & Above college & 0.97 & 0.13 & -0.22 & $0.75 \sim 1.26$ \\
\hline & Unknown & 0.76 & 0.11 & -1.84 & $0.57 \sim 1.02$ \\
\hline \multirow[t]{2}{*}{ Type of cigarette } & Conventional cigarette user & & & & \\
\hline & Duplicate cigarette user & 1.20 & 0.10 & 2.28 & $1.03 \sim 1.41$ \\
\hline Constant & & 0.15 & 0.04 & -6.97 & $0.09 \sim 0.26$ \\
\hline
\end{tabular}

$95 \%$ confidence interval of logistic regression.

disease according to $\operatorname{sex}^{16)}$. Depending on the school grade, compared with middle school students, students in specialized high schools showed lesser symptoms of periodontal disease. This result is contrary to that of previous studies, which indicated that the increase in smoking period with age has harmful effects on health ${ }^{2,9)}$. However, in this study, the characteristics of general and specialized high schools were considered when classifying them by school level, and not based on students' age. Hence, comparative studies based on the characteristics of more subdivided schools should be conducted in the future. There was also a difference according to the type of residence. Even with the correction of other covariates, adolescents living in childcare facilities tended to have more symptoms of periodontal disease than those living with their families (odds ratio, 2.07). During adolescence, the supervision of parents and the degree of interest and affection for their children have a great influence on health and health behavior. If the amount of time spent with parents and not living with their parents negatively affects their health, the frequency of smoking is reduced. Reported to be significantly higher ${ }^{17,18)}$. These findings are consistent with those of previous studies, suggesting that it is necessary to consider the adolescents' home environment as an important factor when developing education programs related to oral health promotion and smoking cessation.

There was a significant difference in the experience of periodontal disease symptoms according to smoking type. Adolescents who smoked duplicate e-cigarettes experienced symptoms of periodontal disease more frequently than those who smoked conventional cigarettes (odds ratio, 
1.20). This result supports that of the existing research, which reported that the subjective health status of duplicate smokers was extremely poor ${ }^{5,13)}$. In terms of oral health, the nicotine content in e-cigarettes constricts the blood vessels, disrupts blood flow to the gingiva, and lowers the oxygen frequency in the periodontal bag, creating an environment in which the causative agent of periodontal disease can grow and affect the periodontals ${ }^{19}$. In addition, since the possibility of exposure to dangerous substances is much higher than that of cigarette smoking alone when conventional cigarettes and e-cigarettes are used repeatedly ${ }^{5,8)}$, management should be implemented according to the smoking type and oral health education and smoking cessation education should be provided to promote oral health.

This was a second data analysis study using data from the 15th Adolescent Health Behavior Survey (2019) and was conducted to identify the factors affecting the periodontal disease symptoms of adolescent conventional cigarette smokers and adolescent duplicate smokers using e-cigarettes. The results of the study showed that duplicate smokers had more symptoms of periodontal disease than those who smoked conventional cigarettes alone. From these results, it was confirmed that smoking cessation counseling according to the smoking type of adolescents and differentiated education for oral health promotion should be provided. This study is significant in that it identified the factors affecting periodontal health by smoking type among adolescents using the representative national statistical data. However, due to the limitation of the secondary data, the use of e-cigarettes alone was not sufficiently considered when classifying smoking types. In addition, the risk factors related to the incidence of oral disease in multiple aspects were not considered. Therefore, further research should be conducted and should provide a more detailed classification of smokers according to smoking types and the smoking rate. Moreover, additional analysis should be performed considering various risk factors.

\section{Notes}

\section{Conflict of interest}

No potential conflict of interest relevant to this article was reported.

\section{Ethical approval}

This study was approved by the Institutional Review Board (IRB) of the Hanyang University (approval number: HYUIRB-202106-007).

\section{Author contributions}

Conceptualization: Eunsuk Ahn. Data acquisition: Eunsuk Ahn and Jin-ha Lee. Formal analysis: Eunsuk Ahn and Jin-ha Lee. Supervision: Eunsuk Ahn. Writingoriginal draft: Eunsuk Ahn and Jin-ha Lee. Writingreview \& editing: Eunsuk Ahn and Jin-ha Lee.

\section{ORCID}

Eunsuk Ahn, https://orcid.org/0000-0002-9404-4826

Jin-ha Lee, https://orcid.org/0000-0002-3062-8216

\section{References}

1. Kim SY, Park J, Ryu SY, Han MA, Choi SW: Factors related to the use and use intention of electronic cigarettes in dental clinic visiting smokers. J Health Info Stat 45: 8-15, 2020. https://doi.org/10.21032/jhis.2020.45.1.8

2. National Center for Chronic Disease Prevention and Health Promotion (US) Office on Smoking and Health: Preventing tobacco use among youth and young adults: a report of the surgeon general. Centers for Disease Control and Prevention (US), Atlanta, 2012.

3. Lee JH, Kim MJ, Kim SJ, et al.: A comparative analysis of electronic cigarette smoking and smoking cessation trial related factors in adolescent: the Korea Youth Risk Behavior Web-based Survey 2014. J Korean Soc Res Nicotine Tob 8: 65-72, 2017. https://doi.org/10.25055/JKSRNT.2017.8.2.65

4. Ministry of Health and Welfare: The Korea Youth Risk Behavior Web-based Survey. Ministry of Health and Welfare, Sejong, 2010.

5. Prochaska JJ: The public health consequences of e-cigarettes: a review by the National Academies of Sciences. A call for more research, a need for regulatory action. Addiction 114: 587-589, 2019. https://doi.org/10.1111/add.14478 
6. Lee HJ, Cho HJ: Stealth use of electronic cigarettes in smoke-free areas in South Korea. J Korean Soc Res Nicotine Tob 11: 75-83, 2020. https://doi.org/10.25055/JKSRNT.2020.11.2.75

7. Huilgol P, Bhatt SP, Biligowda N, Wright NC, Wells JM: Association of e-cigarette use with oral health: a populationbased cross-sectional questionnaire study. J Public Health (Oxf) 41: 354-361, 2019.

https://doi.org/10.1093/pubmed/fdy082

8. Rouabhia M: Impact of electronic cigarettes on oral health: a review. J Can Dent Assoc 86: k7, 2020.

9. Jeong SR, Doo YT, Lee W: Effect on ambulatory dental visitation frequency according to pack-years of smoking. J Korean Data Inf Sci Soc 27: 419-427, 2016. https://doi.org/10.7465/jkdi.2016.27.2.419

10. Kim SA, Smith S, Beauchamp C, et al.: Cariogenic potential of sweet flavors in electronic-cigarette liquids. PLoS One 13: e0203717, 2018 https://doi.org/10.1371/journal.pone.0203717

11. Kumar PS, Clark P, Brinkman MC, Saxena D: Novel nicotine delivery systems. Adv Dent Res 30: 11-15, 2019. https://doi.org/10.1177/0022034519872475

12. Al-Aali KA, Alrabiah M, ArRejaie AS, Abduljabbar T, Vohra F, Akram Z: Peri-implant parameters, tumor necrosis factor-alpha, and interleukin-1 beta levels in vaping individuals. Clin Implant Dent Relat Res 20: 410-415, 2018. https://doi.org/10.1111/cid.12597

13. Amrock SM, Zakhar J, Zhou S, Weitzman M: Perception of e-cigarette harm and its correlation with use among U.S. adolescents. Nicotine Tob Res 17: 330-336, 2015.

https://doi.org/10.1093/ntr/ntu156

14. Park MH, Song HY: Association between adolescent smoking and health behavior and status: comparison between cigarette and e-cigarette. J Korean Public Health Nurs 34: 153-164, 2020.

https://doi.org/10.5932/JKPHN.2020.34.2.153

15. Camenga DR, Kong G, Cavallo DA, et al.: Alternate tobacco product and drug use among adolescents who use electronic cigarettes, cigarettes only, and never smokers. J Adolesc Health 55: 588-591, 2014.

https://doi.org/10.1016/j.jadohealth.2014.06.016

16. Rodriguez FR, Taner B, Weiger R, Walter C: Is smoking a predictor of apical periodontitis? Clin Oral Investig 17: 1947-1955, 2013. https://doi.org/10.1007/s00784-012-0893-z

17. Yim SY, Park MH: Comparison of the factors affecting smoking quit attempts in adolescent smokers according to amount of smoking. J Korea Contents Assoc 17: 622-633, 2017. https://doi.org/10.5392/JKCA.2017.17.07.622

18. Kim JW, Choi JS: An analysis of family structure on children's medical utilization. Korean J Soc Welf 68: 5-27, 2016.

19. Agnihotri R, Gaur S: Implications of tobacco smoking on the oral health of older adults. Geriatr Gerontol Int 14: 526-540, 2014.

https://doi.org/10.1111/ggi.12285 